\title{
Infection behavior, life history, and host parasitism rates of Emblemasoma erro (Diptera: Sarcophagidae), an acoustically hunting parasitoid of the cicada Tibicen dorsatus (Hemiptera: Cicadidae)
}

Brian J Stucky

\begin{abstract}
Background: 'Eavesdropping' parasitoids find their hosts by homing in on the communication signals of other insects. These parasitoids often exploit chemical communication, but at least some species of the sarcophagid genus Emblemasoma eavesdrop on the acoustic communications of cicadas. Despite considerable scientific interest in acoustic parasitoids, we know remarkably little about most species of Emblemasoma. To better understand the ecology and behavioral diversity of these flies, I used a combination of field and laboratory techniques to elucidate the infection behavior and life history of E. erro, which uses the cicada Tibicen dorsatus as a host, and I also investigated parasitoid loads and parasitism rates of T. dorsatus in multiple host populations in the central United States.

Results: Female E. erro used the acoustic signals of male T. dorsatus as the primary means of locating hosts, but they also required physical movement by the host, usually either walking or flight, to provide visual cues for the final larviposition attack. Larvae were deposited directly on the host's integument and burrowed through intersegmental membrane to enter the host's body. On average, E. erro larvae spent $88.0 \mathrm{~h}$ residing inside their host before leaving to pupariate, but residence time was strongly dependent on both ambient temperature and effective clutch size. Adult flies eclosed about 18 days after pupariation. Across all study sites, the mean parasitoid load of infected male T. dorsatus was 4.97 larvae/host, and the overall parasitism rate was 26.3\%. Parasitism rates and parasitoid loads varied considerably among host population samples, and high parasitism rates were usually associated with high parasitoid loads.

Conclusions: Previously, detailed information about the infection behavior, life history, and host parasitism rates of sarcophagid acoustic parasitoids was only available for one species, E. auditrix. This study reveals that the infection behavior of E. erro is quite different from that of E. auditrix and, more broadly, unlike that known for any other species of acoustic parasitoid. The life histories of these two Emblemasoma are also divergent. These differences suggest that sarcophagid acoustic parasitoids are more behaviorally and ecologically diverse than previously recognized and in need of further study.
\end{abstract}

Keywords: Eavesdropping; Emblemasoma; Host defense; Host location; Infection behavior; Parasitoid; Parasitoid load; Phonotaxis; Superparasitism; Tibicen

Correspondence: stuckyb@colorado.edu

Department of Ecology and Evolutionary Biology, University of Colorado,

Campus Box 334 UCB, Boulder, CO 80309, USA 


\section{Background}

For female parasitoids, successful reproduction usually requires finding suitable hosts for their offspring. The problem, of course, is that potential hosts generally do their best not to be found. Sometimes, however, even well-hidden host insects must produce intraspecific communication signals, and these communication signals can be exploited by specialist parasitoids for use in efficient, long-range host location (Godfray 1994; Zuk and Kolluru 1998; Haynes and Yeargan 1999). Most often, such 'eavesdropping' parasitoids intercept chemical communications, but several species of flies (Diptera) from two families, Sarcophagidae and Tachinidae, use acoustic signals to find their hosts (Cade 1975; Soper et al. 1976; Lakes-Harlan and Lehmann 2015). Acoustically orienting tachinid parasitoids (tribe Ormiini) parasitize crickets and katydids (Orthoptera) (Lehmann 2003), while sarcophagid acoustic parasitoids, which are currently placed in the genus Emblemasoma (sensu Pape (1990)), parasitize cicadas (Hemiptera: Cicadidae) (Soper et al. 1976; Schniederkötter and Lakes-Harlan 2004). Because acoustic signals are often more amenable to experimental manipulation than pheromones, acoustic parasitoids have become valuable model organisms for investigating sexual signal exploitation and its consequences (e.g., Adamo et al. 1995; Allen 1998; Gray and Cade 1999; Müller and Robert 2002; Lehmann and Lehmann 2006; Beckers and Wagner 2011).

However, current knowledge of acoustic parasitoids is heavily biased toward the ormiine tachinids, which have received the majority of research (reviewed in Lehmann 2003). In comparison, our understanding of sarcophagid acoustic parasitoids is far more limited. Emblemasoma includes 16 described species (Pape 1996), but nearly everything known about the basic biology, behaviors, and ecology of these flies comes from study of a single species, Emblemasoma auditrix (Shewell), which is a specialist parasitoid of the cicada Okanagana rimosa (Say) (e.g., Lakes-Harlan et al. 2000; Köhler and Lakes-Harlan 2001; Schniederkötter and Lakes-Harlan 2004). No detailed information is available about the infection behaviors or life histories of any other Emblemasoma, and the only other record of phonotactic behavior comes from a study in which the species of Emblemasoma was not determined (Farris et al. 2008). Furthermore, no information about host parasitism rates or parasitoid loads is available for any species besides $E$. auditrix and its host O. rimosa.

Considering that Emblemasoma are frequently referenced in discussions of insect hearing and parasitoid biology (e.g., Godfray 1994; Feener and Brown 1997; Yager 1999; Yack 2004; Robert 2005; Hedwig and Robert 2014; Strauß and Lakes-Harlan 2014) and that their 'ears' have been the focus of multiple physiological investigations (Lakes-Harlan et al. 1999; Robert et al. 1999; Farris et al. 2008), it is perhaps surprising how little we actually know about the basic biology and ecology of any of these flies besides $E$. auditrix. As a consequence, it is nearly impossible to make meaningful generalizations about sarcophagid acoustic parasitoids, and drawing broader conclusions about acoustically orienting parasitoids in general is similarly difficult.

In 2008, I discovered that adults of the cicada Tibicen dorsatus (Say) (Figure 1), a large cicada that is common in the grasslands of central North America (Cole 2008), were sometimes infected with the larvae of a sarcophagid parasitoid. After a preliminary investigation revealed that this parasitoid was Emblemasoma erro Aldrich (Figure 2) and that these flies were most likely locating their hosts acoustically, I began a comprehensive study of the basic biology of this fly. The only information previously available about the biology of $E$. erro was a record of a single female fly that had been reared from a specimen of the cicada Quesada gigas (Olivier) in Brazil (Lopes 1981) and a report of rearings from Tibicen sp. in Texas, USA (Lakes-Harlan 2009).

In this paper, I 1) describe the host locating and larviposition behaviors of E. erro; 2) describe this parasitoid's life history; and 3) report the results of an investigation of parasitism rates and parasitoid loads in natural populations of the host cicada, $T$. dorsatus. I then discuss the following: the infection behaviors of E. erro in comparison with other acoustic parasitoids and other sarcophagid parasitoids, potential host defenses, and the causes of variation in host population parasitism rates and parasitoid loads, including empirical evidence that superparasitism might contribute to high parasitoid loads in some host populations. The results show not only that the behaviors and life histories of sarcophagid acoustic parasitoids are more diverse than previously recognized, but also that the infection behaviors of E. erro are unlike those known for any other acoustic parasitoid.

\section{Methods}

\section{Study sites}

Surveys of host populations, collections of adult hosts and parasitoids, and field behavioral observations were conducted at six primary study sites located in Ellsworth, Harvey, McPherson, and Reno counties in central Kansas, Hamilton County in western Kansas, and Prowers County in eastern Colorado (Figure 3). The central Kansas sites are located within the Central Great Plains level III ecoregion, while the western Kansas and eastern Colorado sites are located near the boundary between the High Plains and Southwestern Tablelands ecoregions (US Environmental Protection Agency 2013). All sites consisted of native midgrass or shortgrass prairie vegetation intermixed with riparian, woody vegetation, or 


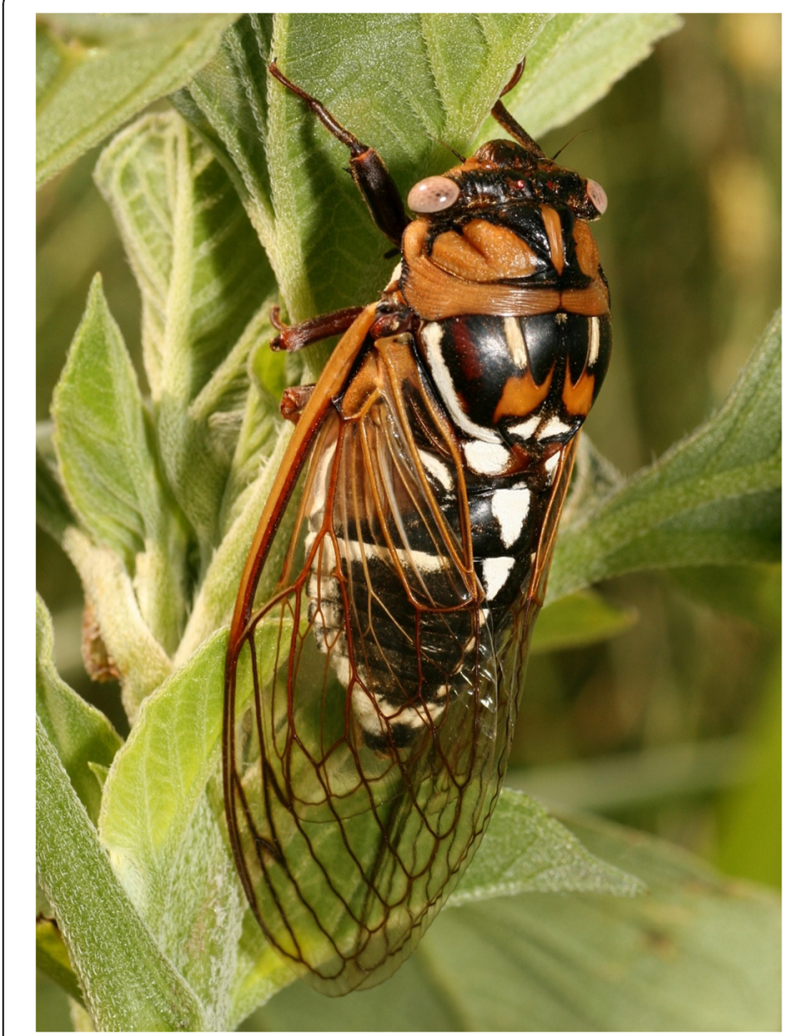

Figure 1 Male Tibicen dorsatus, Harvey Co., KS.

planted trees. Supplemental collections of host cicadas and adult flies for life history and behavioral study were made at five additional locations in Kansas with habitat that was similar to that at the primary study sites (Figure 3).

\section{Host locating and larviposition behaviors of $E$. erro}

The host locating and larviposition behaviors of E. erro were studied in three ways. First, natural cicada/fly interactions were observed directly in the field whenever possible during the summers of 2010 to 2014. Second, artificial broadcasts of acoustic stimuli were used to test for phonotactic behavior by female flies in the field; and third, cicada/fly interactions were observed in a controlled, outdoor laboratory environment. The methods for these latter two approaches are next described in more detail.

\section{Field broadcasts of acoustic stimuli}

Preliminary observations suggested that male cicadas' acoustic signals played a role in host location by E. erro, but such observations cannot assess whether acoustic cues by themselves are sufficient to attract female parasitoids. To separate acoustic stimuli from other possible sources of information about the location of potential hosts (e.g., visual or olfactory), a loudspeaker was used in the field to broadcast audio that mimicked the calling song of a typical male $T$. dorsatus.

Acoustic signals for attracting E. erro were generated by gathering audio recordings of calling male $T$. dorsatus, analyzing these recordings to estimate the mean values of several acoustic parameters, then constructing model acoustic signals that matched, as closely as possible, the mean calling song of the species. To ensure that the model acoustic signals were broadly representative of $T$. dorsatus from the general study area, I obtained recordings of 20 different individuals of $T$. dorsatus from six field sites in Kansas. All recordings were made as uncompressed, 16-bit PCM audio at a sampling rate of $44.1 \mathrm{kHz}$ using a highly directional shotgun microphone (Sennheiser ME66 or ME67 with a matched windscreen; Sennheiser Electronic GmbH \& Co. KG, Hannover, Germany) and a digital audio recorder (Sony MZ-M200 or PCM-M10; Sony Corporation, Tokyo, Japan). To minimize background noise while also avoiding nearfield acoustic effects in the frequency range of the cicadas' calling songs (Michelsen and Nocke 1974; Peterson 1980), recordings were typically made with the microphone held at a distance of between 0.5 and $2 \mathrm{~m}$ from the calling cicada. Most recordings were made directly in the field, but in some cases, cicadas were captured and placed in mesh cages, then recorded once they resumed normal acoustic activity.

Each recording was analyzed to determine the values of three acoustic variables: peak frequency, pulse group (PG) length, and PG rate. A 'pulse group' is defined as a first-order assemblage of sound pulses (i.e., a train of sound pulses) that is separated by silence from the rest of the audio signal. It is the basic unit of temporal structure in the call of $T$. dorsatus (see Cole (2008) for a spectrogram and oscillogram of the $T$. dorsatus calling song; note that Cole refers to PGs as 'syllables'). Peak frequency was estimated by identifying the highest peak in a power spectral density plot generated by Audacity ${ }^{\circ}$ (Audacity Team 2012) using a 512-sample fast Fourier transform with the Hann window function. If there were two or more peak frequencies that differed by less than $0.5 \mathrm{~dB}$, their average was taken as the overall peak frequency. PG length and rate were determined using custom-written software to analyze $10 \mathrm{~s}$ of audio from the middle of each calling song recording. Following these analyses, a single model acoustic signal was constructed using the $T$. dorsatus recording that was as close as possible to the mean calling song observed for the species (mean peak frequency $=4,308 \mathrm{~Hz}[s=444]$; mean PG length $=20.3 \mathrm{~ms}[s=1.45]$; mean $\mathrm{PG}$ rate $=$ 37.04 PG/s $[s=2.25])$. I also generated synthetic acoustic signals constructed from amplitude-modulated sine waves that exactly matched the observed mean acoustic variable values. 


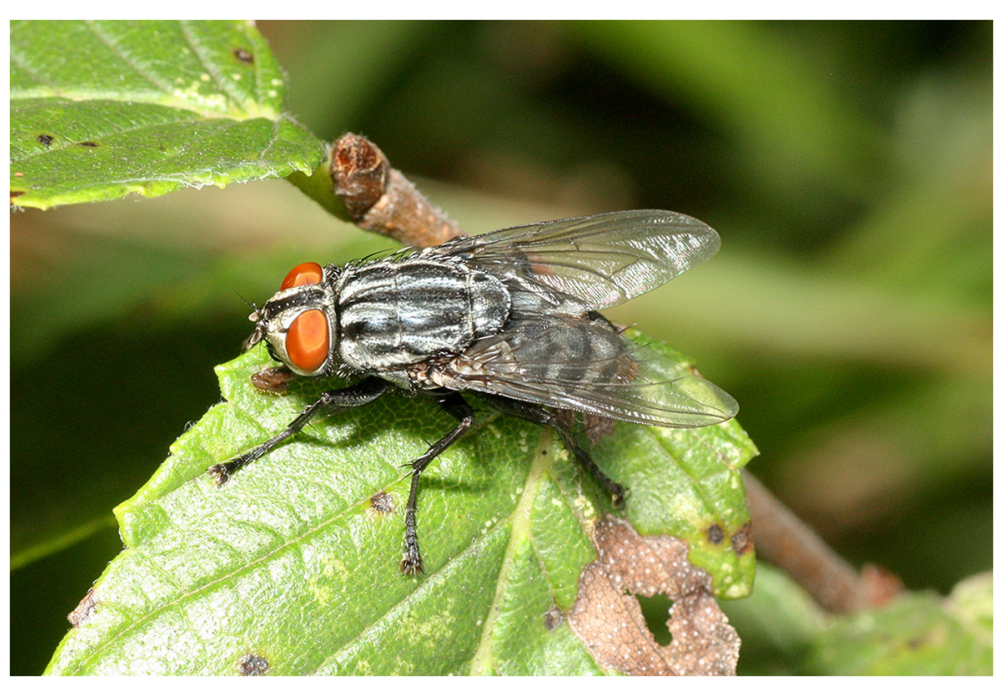

Figure 2 Female Emblemasoma erro, Ellsworth Co., KS.

Acoustic signals were broadcast in the field with a custom-built, portable broadcasting system consisting of a 12-V audio amplifier and a high-output, horn-loaded tweeter speaker (PylePro PH44; Pyle Audio Inc., Brooklyn, NY, USA) mounted in the top of a wooden box. Acoustic signals were fed to the amplifier from either a portable $\mathrm{CD}$ player or a flash memory-based digital audio player. Broadcasts in the field were conducted either in the late morning or afternoon when cicadas were naturally active, usually for a duration of 4 to $8 \mathrm{~min}$ at one time. Flies that were attracted to the broadcast speaker were captured by hand.

\section{Laboratory observations}

Although natural cicada/fly interactions were occasionally observed in the field, opportunities for such observation were unpredictable and infrequent. Furthermore, closerange observation was often impossible, and cicadas could rarely be captured after an encounter with a fly to determine whether larviposition occurred. Consequently, observation of cicada/fly interactions in a more controlled setting was also necessary.

Initial attempts to observe the infection behavior of $E$. erro in 2010 used restrained cicadas and audio broadcasts in an approach similar to that used by Schniederkötter

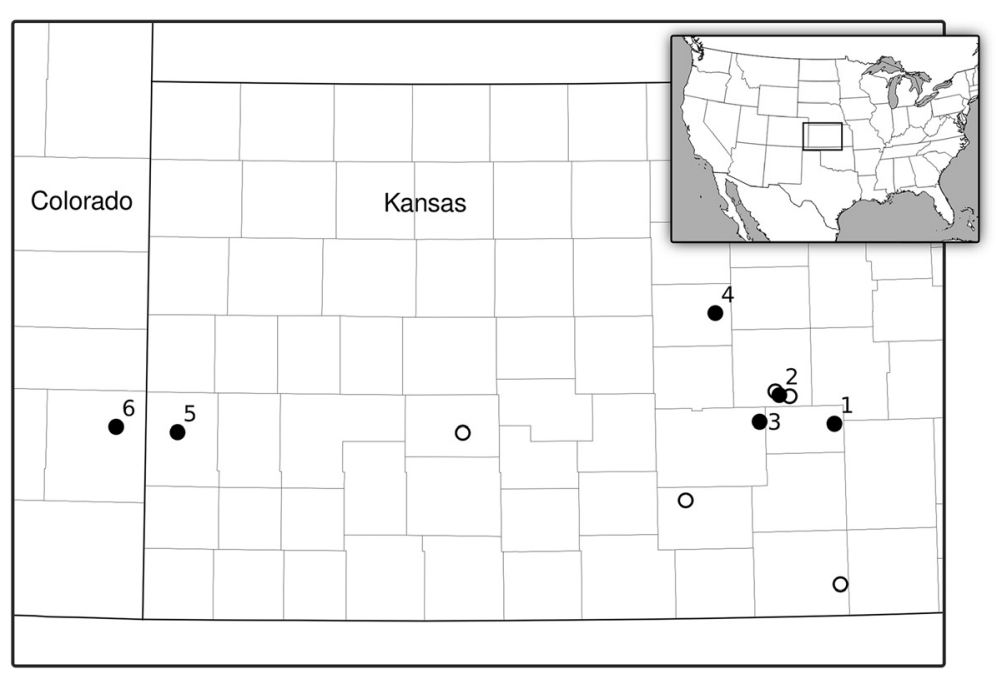

Figure 3 Locations of study sites. Filled circles indicate the primary sites used for estimating host parasitism rates, and open circles indicate secondary sites used for additional collections of cicadas and flies. Primary sites are referenced in the text by the counties in which they were located: 1) Harvey Co., 2) McPherson Co., 3) Reno Co., 4) Ellsworth Co., 5) Hamilton Co., and 6) Prowers Co. Both T. dorsatus and E. erro were found at all 11 sites. The inset map indicates the location of the main map in the United States, 
and Lakes-Harlan (2004) for their study of E. auditrix. This technique was unsuccessful for $E$. erro, however, so further experiments with immobilized cicadas were abandoned.

Instead, unrestrained cicadas and flies were allowed to freely interact in outdoor cages during behavioral experiments in 2012 and 2013. For each infection behavior trial, one female fly was released into a mesh cage containing one or two uninfected male cicadas. Three types of cage were used: a cylindrical cloth mesh cage approximately $27 \mathrm{~cm}$ in diameter and $39 \mathrm{~cm}$ high; a larger cylindrical cloth mesh cage approximately $46 \mathrm{~cm}$ in diameter and $66 \mathrm{~cm}$ high; and a much larger, rectangular screen 'flight cage' with a square base and walls approximately $1.8 \mathrm{~m}$ on each side and just over $2.1 \mathrm{~m}$ high at the center of the top. The behaviors of the fly and cicada(s) were then observed carefully throughout the duration of the trial. If the fly appeared to directly contact the cicada with the tip of her abdomen or otherwise attack the cicada, the cicada was immediately removed and inspected for the presence of fly larvae. In most trials, the cicada and fly were not physically disturbed inside of the cage, but in some cases the cicada was induced to flight by the experimenter to observe the fly's response. Trials ended when a fly larviposited upon a cicada or the fly no longer showed interest in the cicada(s) in the cage. To avoid overly stressing the animals, trials were also usually terminated after a fly made several attempts to attack a cicada even if larviposition was not observed. If the infection status of a cicada could not be determined by visual inspection immediately after a trial, the cicada was not used in further trials for at least $48 \mathrm{~h}$ in order to verify whether it had become infected. No single female fly was used to infect more than two cicadas. Whenever a fly larviposited on a cicada, I attempted to immediately count the number of larvae deposited. This was not always possible, though, and in these cases, the total number of larvae was determined by rearing the parasitoids or dissecting the host.

All cicadas used for this part of the study were mature adult male $T$. dorsatus that were captured directly in the field. Captured cicadas were maintained outdoors in large cloth mesh cages placed over live branches of green ash (Fraxinus pennsylvanica), which provided the cicadas with a suitable food source. After capture, and before exposing them to parasitoids, all cicadas were closely monitored for up to 9 days to determine whether they had already been parasitized in the field by E. erro. Only unparasitized cicadas were used for studying cicada/ fly interactions. Adult female E. erro were obtained by broadcasting the model call of $T$. dorsatus in the field, as described above, and collecting attracted female flies by hand. Flies were kept in small mesh cages in the laboratory and provided with sucrose and water ad libitum.

\section{Life history of $E$. erro}

The timings of key life history events for E. erro were estimated by rearing parasitoids from hosts that were naturally infected in the field, infected during the behavior studies described above, or artificially infected in the lab. To artificially infect cicadas in the laboratory, a female $E$. erro was first anesthetized by chilling the insect at approximately $4^{\circ} \mathrm{C}$ for several minutes. The fly was then decapitated, placed on a piece of moistened filter paper on a watch glass, and live first-instar larvae were carefully dissected from the fly's abdomen. Individual larvae were transferred to uninfected adult $T$. dorsatus cicadas using the moistened tip of a fine artist's brush. Most larvae were placed on the intersegmental membrane at the base of the cicada's wings, but some were placed at the lateral junction of the metathorax and mesothorax or the junction of the metathorax and the first abdominal tergum. A fine insect pin was sometimes used to make a small puncture in the membrane at the wing base in order to facilitate the larvae's entry into the host's body. Larvae from a single female fly were never used to infect more than two cicadas.

All infected cicadas were kept in outdoor, mesh cages as described above. Cicadas were checked several times daily, and any individuals that died or appeared moribund were moved indoors into small plastic emergence containers to capture emerging fly larvae. Once a host was moved to a larval emergence container, video recording was used to capture the precise time and location of larval egress from the host. If no larvae were observed in an emergence container approximately $48 \mathrm{~h}$ after host death, or if only undersized larvae emerged, the dead cicada was dissected to check for additional fly larvae.

Parasitoid larvae that emerged from their host were provided with fine sand in which to burrow and pupariate. Once pupariation was complete, bits of moist paper towels were placed in the emergence containers to help maintain suitable humidity, and the puparia were kept at room temperature (generally $24^{\circ} \mathrm{C}$ to $28^{\circ} \mathrm{C}$ ) and exposed to the approximate natural daily photoperiod. The emergence containers were fitted with screen tops to capture any eclosing adult flies.

To better understand how biotic and abiotic factors influence larval development, I evaluated the effects of two key variables - effective clutch size (the number of larvae from a clutch that successfully develop inside a host) and the ambient temperature experienced by the host - on the total time larval parasitoids spent inside their host (the 'larval residence time'). These variables were chosen because temperature affects the development and growth rates of insects in general (Harrison et al. 2012), and the number of larvae inside a host might influence how rapidly the host is consumed. For 
this analysis, larval residence time was calculated as the total elapsed time, in hours, from the moment a larva was deposited on a cicada until the larva emerged from its host. Effective clutch size was taken as the total number of larvae that emerged from a host (because the host cicadas for this analysis were infected in the behavior studies or in the lab, all larvae inside a host were known to be from the same clutch). Temperature was calculated as the mean ambient air temperature experienced by each parasitized host. Temperature data were taken from the Daymet $1-\mathrm{km}$ daily surface weather dataset (Thornton et al. 1997, 2014). The overall mean ambient air temperature experienced by a parasitized cicada was estimated by averaging the daily minimum and maximum temperatures for each day that the cicada was infected up to the time of larval egress from the host. The relationship among these three variables was analyzed using multiple linear regression with effective clutch size and temperature as the explanatory variables. To avoid potential non-independence problems caused by related larvae sharing the same host cicada, the data were summarized at the level of the host cicada; that is, for each host with multiple parasitoid larvae, the mean residence time for all larvae from the host was used in the analysis instead of the residence time for each parasitoid larva. Diagnostic plots of the standardized residuals were used to verify the fit of the regression model. This, and all other statistical analyses, was conducted in $\mathrm{R}$ version 3.1.1 (R Core Team 2014). Note that larvae from parasitized cicadas captured in the field could not be included in this analysis because it was not known when these larvae were deposited on their hosts.

\section{Host parasitism rates and parasitoid loads}

To obtain population samples for estimating host parasitism rates, adult $T$. dorsatus were surveyed by walking through the habitat at a study site and attempting to capture all $T$. dorsatus that were observed perched in the vegetation or disturbed into flight. Teneral or recently emerged cicadas were excluded because male cicadas do not develop full calling capabilities or begin sexual acoustic behaviors until several days after eclosion (Maier 1982; B. Stucky, unpublished data). Captured cicadas were maintained in captivity to rear the parasitoids from all infected cicadas, determine the total number of infected cicadas in each sample, and determine the parasitoid load of each host, following the methods described above.

Cicada population surveys were conducted at the six primary study sites in July, August, or early September of 2011 to 2014, although not all sites were sampled all 3 years (Table 1). The survey dates were limited by when adult $T$. dorsatus were actually present in the field, which varied from year to year. In 2012, for example, adult $T$. dorsatus were abundant in central KS by July 1 , but they did not reach similar abundance in 2013 until the latter half of July.

By the time the first population samples were collected in 2011, I had established that the male cicada's calling song was a critical cue used by female parasitoids to locate their hosts. Consequently, surveys from 2011 to 2013 focused on male cicadas only (females do not produce sound) in order to use the limited space available for housing these large insects as efficiently as possible. In 2014, both female and male cicadas were sampled at the field sites in Harvey, McPherson, and Reno counties in central Kansas.

Logistic regression (generalized linear models with binomial-distributed response and logit link function) was used to evaluate whether host parasitism rates varied among the field sites and whether sample year or sample date also influenced parasitism rates. The proportion of parasitized cicadas in population samples was modeled with field site, year, and ordinal sample date as possible predictor variables. Both field site and year were treated as categorical variables. To test the effects of individual predictors and decide which variables to retain in the model, nested models were compared using the difference of their deviance statistics (i.e., likelihood-ratio tests) (Dobson and Barnett 2008). Standardized residuals plots were examined to check for any problems with model specification. To further assess the final model fit, the likelihood-ratio (also known as McFadden) pseudo $R^{2}$ was calculated (McFadden 1974; Menard 2000).

Early in this study, it became clear that parasitoid loads varied among the population samples. One possible cause of such variation is superparasitism, which, for gregarious parasitoids such as E. erro, is expected to occur more often when unparasitized hosts are rare (Godfray 1994). Unparasitized hosts are rare when parasitism rates are high, so to test for this causal relationship, I used simple linear regression to evaluate whether high host parasitism rates corresponded with high parasitoid loads. For this analysis, each data point was the estimated mean host parasitoid load and parasitism rate for a single study site in a given year. Yearly population samples for which fewer than three parasitized cicadas were available to estimate the mean parasitoid load were excluded from the analysis. Parasitism rate was used as the explanatory (i.e., $\mathrm{x}$-axis) variable, and because parasitism rates were estimated from population samples, some of which were small, there was the possibility of substantial measurement error. Consequently, the regression analysis was likely to suffer from slope attenuation bias, in which the slope estimator is biased to be less than the true slope (Bulmer 1979; Smith 2009). To compensate for this, I used the sizes of each population sample to estimate the mean measurement error variance across all population samples. I then used this estimate of 
Table 1 Observed parasitism rates of male $T$. dorsatus in the field

\begin{tabular}{|c|c|c|c|c|c|c|}
\hline Study site & Dates & Infected & Uninfected & Total & $\%$ infected & $95 \% \mathrm{Cl}$ \\
\hline \multirow[t]{4}{*}{ McPherson Co. } & Site summary (2012 to 2014) & 3 & 45 & 48 & 6.3 & 2.1 to 16.8 \\
\hline & 2012: July 2, 4 & 0 & 12 & 12 & 0.0 & \\
\hline & 2013: Aug. 2, 20 & 0 & 10 & 10 & 0.0 & \\
\hline & 2014: Aug. 3, 12 & 3 & 23 & 26 & 11.5 & \\
\hline \multirow[t]{3}{*}{ Prowers Co. } & Site summary (2013 to 2014) & 27 & 9 & 36 & 75.0 & 58.9 to 86.2 \\
\hline & 2013: Aug. 22, 28 & 11 & 4 & 15 & 73.3 & \\
\hline & 2014: Aug. 21, Sept. 4 & 16 & 5 & 21 & 76.2 & \\
\hline \multirow[t]{3}{*}{ Hamilton Co. } & Site summary (2013 to 2014) & 10 & 3 & 13 & 76.9 & 49.7 to 91.8 \\
\hline & 2013: Aug. 22, 28 & 6 & 3 & 9 & 66.7 & \\
\hline & 2014: Aug. 21 & 4 & 0 & 4 & 100.0 & \\
\hline \multirow[t]{5}{*}{ Harvey Co. } & Site summary (2011 to 2014) & 11 & 51 & 62 & 17.7 & 10.2 to 29.0 \\
\hline & 2011: Aug. 12 & 1 & 9 & 10 & 10.0 & \\
\hline & 2012: July 7, 12 & 5 & 13 & 18 & 27.8 & \\
\hline & 2013: Aug. 5, 12 & 3 & 14 & 17 & 17.6 & \\
\hline & 2014: Aug. 9, 12 & 2 & 15 & 17 & 11.8 & \\
\hline \multirow[t]{5}{*}{ Reno Co. } & Site summary (2011 to 2014) & 8 & 65 & 73 & 11.0 & 5.7 to 20.2 \\
\hline & 2011: Aug. 14, 15 & 1 & 3 & 4 & 25.0 & \\
\hline & 2012: July 16, Aug. 17 & 1 & 13 & 14 & 7.1 & \\
\hline & 2013: July 23 & 0 & 15 & 15 & 0.0 & \\
\hline & 2014: Aug. 4, 11 & 6 & 34 & 40 & 15.0 & \\
\hline \multirow[t]{5}{*}{ Ellsworth Co. } & Site summary (2011 to 2013) & 11 & 23 & 34 & 32.4 & 19.1 to 49.2 \\
\hline & 2011: Aug. 11 & 5 & 3 & 8 & 62.5 & \\
\hline & 2012: Aug. 19 & 2 & 1 & 3 & 66.7 & \\
\hline & 2013: Aug. 10, 17 & 4 & 19 & 23 & 17.4 & \\
\hline & Overall & 70 & 196 & 266 & 26.3 & 21.4 to 31.9 \\
\hline
\end{tabular}

Observed parasitism rates are given for each study site for all sample years combined, with the yearly observations for each site given below the site summary rows. The overall totals for all sites and years combined are given at the bottom of the table. 'Infected' is the number of parasitized cicadas that were captured, 'Uninfected' is the number of unparasitized cicadas, 'Total' is the total number of cicadas captured, and ' $95 \%$ Cl' is the Wilson $95 \%$ confidence interval for the population estimate of the percentage of infected male cicadas. Refer to Figure 3 for study site locations.

the error variance with the method of moments estimator (MME) of the bias correction factor (Carroll and Ruppert 1996; Smith 2009) to calculate an attenuation-corrected slope estimate. Diagnostic plots of the standardized residuals were used to verify the fit of the simple linear regression model.

\section{Additional statistical methods}

All confidence intervals (CIs) for population proportion estimates were calculated using the Wilson method (also known as the score confidence interval) because of its good performance across a broad range of sample sizes (Wilson 1927; Agresti and Coull 1998). CIs for the estimates of population means were constructed using the standard $t$-distribution method when possible (Whitlock and Schluter 2009), but in cases where the population distribution appeared to be non-normal (as determined by examining plots of sample distributions), CIs were calculated using the bootstrap- $t$ resampling method with
1,000,000 replicates (Efron and Tibshirani 1993; Carpenter and Bithell 2000). Bootstrap-t resampling with 1,000,000 replicates was also used to compare the means of nonnormally distributed populations. Throughout this paper, ' $s$ ' is used to indicate the sample standard deviation.

\section{Results}

\section{Host locating and larviposition behaviors of E. erro} Host locating behavior

Field and laboratory observations of cicada/fly interactions and field broadcasts of the $T$. dorsatus call all confirmed that E. erro uses the calling songs of male cicadas as the primary cue for locating potential hosts. In the field, I was able to observe, at relatively close range, the interactions between $14 T$. dorsatus cicadas and E. erro flies. All of the cicadas involved in these interactions were males, 13 of which were acoustically active while I observed them. Seven individual flies were observed in the process of locating a perched cicada (either by flight 
or walking), and in every case, the perched cicada was calling while the fly was moving toward it. In the other observed cicada/fly interactions, the flies were already perched near the cicada when I first saw them and I did not observe how, or when, the flies actually arrived near these cicadas. I never saw flies near perched female cicadas, which cannot produce sound.

During the infection behavior trials in outdoor cages in 2012 and 2013, female flies in the experiment cages typically showed an immediate, strong phonotactic response to calling cicadas. When a cicada in the cage began to call, a fly would either walk towards the calling cicada, fly to within several centimeters of the cicada and then walk towards it, or, in some cases, fly directly to, and land on, the calling cicada. Thus, both field and laboratory observations of cicada/fly interactions provided strong circumstantial evidence that $E$. erro use the acoustic calls of cicadas to locate their hosts, but such observations cannot definitively rule out the possibility that some other source of information was actually being used, such as visual or olfactory cues.

Field broadcasts of the model $T$. dorsatus calling song furnished unambiguous evidence that acoustic cues, by themselves, are sufficient to attract female flies. The model $T$. dorsatus calling song was broadcast at least once at all six primary field sites. E. erro were attracted to the broadcast speaker at every location. Flies often arrived within a few seconds of the start of a broadcast, and it was not uncommon to see multiple flies perched on the top of the speaker box at the same time. At least two or more flies were collected at each primary field site, and more than 60 E. erro in total were captured during this study. Often, many more flies arrived at the broadcast speaker than could be captured by hand. I did not attempt to quantify the number of flies that arrived and were not captured, however, because individual flies will sometimes arrive at and leave the speaker multiple times during a single broadcast (B. Stucky, personal observation), making any such counts unreliable. The broadcast apparatus never attracted any flies when the loudspeaker was not operating.

\section{Larviposition behavior}

Acoustic cues and phonotaxis are clearly critical for $E$. erro to locate its hosts, but the calling song by itself never induced $E$. erro to larviposit in the absence of a host. Despite the large numbers of flies that were attracted to the calling song broadcasts, no fly larvae were ever found on the speaker or surface of the speaker box following a broadcast of the model $T$. dorsatus call.

Furthermore, laboratory observations of infection behaviors revealed that, even when a potential host was present, the cicada's calling song was still not the stimulus that ultimately triggered larviposition. Although cicadas often called during the infection behavior trials in 2012 and 2013, in no case did this directly result in larviposition by a female fly. Instead, once a fly had moved to within a few centimeters of a calling cicada by orienting to the cicada's calling song, it would typically remain more or less stationary next to the cicada with its head facing toward the cicada's body. At this point, repeated calls from the cicada usually resulted in relatively little additional movement from the fly. However, if the cicada moved either by walking or flight, the fly usually attempted to maintain its proximity to the potential host. Thus, if the cicada began walking, the fly would typically follow it from a short distance (e.g., 2 to $3 \mathrm{~cm}$ away). If the cicada took flight, the fly almost always immediately took flight as well and attempted to follow the cicada in the air.

Sometimes, cicada locomotion resulted in a larviposition attack by the fly, and all evidence suggested that at least some movement by the cicada was essential for larviposition. Seventeen incidents of successful larviposition were obtained during the infection behavior trials in 2012 and 2013, and in every case, larviposition was only observed when cicadas were in motion. I was able to determine the moment of larviposition for 15 of these attacks. Of these, five $(33.3 \%)$ occurred while the cicada was in flight; the remaining ten attacks (66.7\%) occurred while the cicada was either walking, flapping its wings, or both. In a few cases, the cicadas that were attacked never called at all during the time the fly was in the cage. These cicadas were 'discovered' by the flies purely due to their physical movement in the cage, further indicating that movement by a potential host, not sound, provides the visual cues that ultimately trigger larviposition. As a further example, in 2012, I experimented with releasing a female $T$. dorsatus (which cannot produce sound at all) in the air in front of a female fly. The fly eventually followed the cicada and larviposited on it in flight.

Successful larviposition attempts resulted in the deposition of one or more tiny first-instar larvae directly upon the exterior of the cicada's body (Figure 4). A sticky secretion also usually accompanied the larvae, presumably to help them adhere to the host. Flies appeared to briefly contact the cicada with their abdomens during larviposition, but high-speed video recording would be needed to reveal the exact mechanics of this process. After larviposition, the larvae immediately began searching for an area of intersegmental membrane through which to burrow and enter the host's body. The larvae typically entered the host quite rapidly, disappearing after anywhere from a matter of seconds to a few minutes.

Although the location of larvae deposition could not be determined in all cases because the larvae sometimes disappeared into the host's body before they could be observed, the evidence suggests that flies prefer to attack 


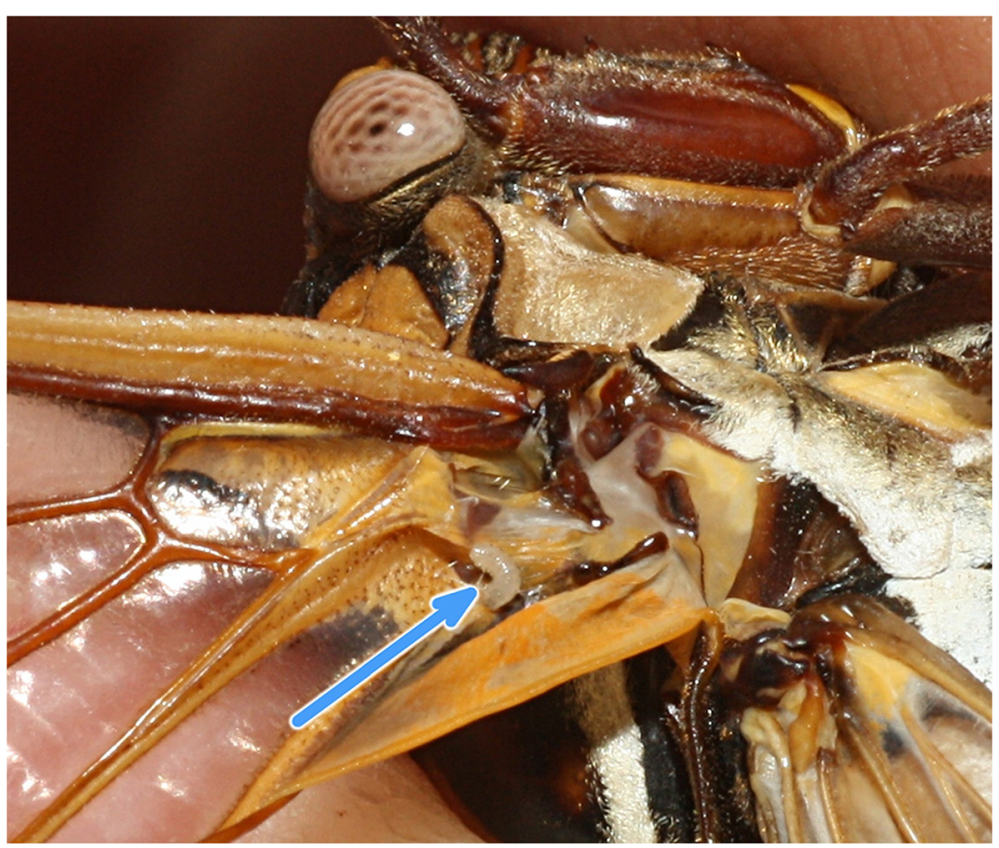

Figure 4 Larviposition by E. erro. A first-instar larva of E. erro on the right fore wing of a T. dorsatus moments after larviposition (larva indicated by blue arrow). The cicada's head and foreleg are at top center.

the base of a host's wings. Of 15 attacks for which the exact location of larviposition was determined (out of 17 total successful attacks), 1 (6.7\%) was on the base of a fore leg, $2(13.3 \%)$ were on the abdomen, and $12(80 \%)$ were either directly on the wings (usually near the base) or on the pterothorax or the first two abdominal segments next to the base of the wings. Left/right orientation was recorded for 14 of the 15 attacks, and of these, $9(64.3 \%)$ were on the left side of the cicada's body, 3 (21.4\%) were on the right side, and $2(14.3 \%)$ were approximately medial. In their studies of the infection behaviors of E. auditrix, Schniederkötter and Lakes-Harlan (2004) discovered that $E$. auditrix preferentially attacked the left side of potential hosts. Most laterally oriented attacks by E. erro also occurred on the left side of the cicada's body ( 9 of 12, or $75 \%$ ), but this asymmetry was not statistically significant for this sample size (exact binomial test, $p=0.146$ ).

The number of larvae deposited by a single female fly on a host cicada during the infection behavior trials (i.e., the clutch size) varied from a minimum of one to a maximum of six, but more than $80 \%$ of the time, flies (14 of 17) deposited three or fewer larvae. The mean clutch size was 2.53 (95\% bootstrap- $t$ CI: 1.85 to 3.45 larvae/host, $s=1.50$, $n=17$ hosts) and the median was 3 .

Observations of fly behavior in the field appeared to corroborate the infection behaviors in the lab. I observed eight male $T$. dorsatus that each produced one or more complete calling songs (as many as five in one case) while an E. erro was perched next to the cicada. In no case did the calling song appear to trigger an attempt at larviposition. Just as in the laboratory, flies often waited, nearly motionless, next to calling cicadas, and if a cicada in the field crawled up or down the vegetation it was perched on, the fly usually followed it. If the cicada took flight, the fly usually also took flight and followed the cicada in the air.

As in the cage infection behavior trials, flies in the field only seemed to attack a cicada if the cicada was in motion or had just moved, and most apparent attacks occurred when the cicada was in flight. On two such occasions, cicadas that were evidently struck in the air by E. erro had their flight disrupted to such an extent that the cicadas crashed to the ground. Unfortunately, I could not determine with absolute certainty whether any of the flies I observed in the field actually larviposited on the attacked cicadas. I was able to capture eight cicadas shortly after their interactions with E. erro, but I was unable to locate first-instar fly larvae on any of them. Considering how rapidly larvae can burrow into their host's body, it is likely that they had already disappeared from view by the time I was able to look for them. Parasitoids were reared from all eight cicadas, though, so it is very likely that at least some became infected during the observed cicada/fly interactions.

\section{Life history of $E$. erro}

From the moment of larviposition until they completely exited the host's body, E. erro larvae spent, on average, $88.0 \mathrm{~h}$ residing inside their host (95\% CI: 81.19 to 
94.76 h, $s=17.1, n=27$ larvae from 13 host cicadas and 10 female flies, range $=61.3$ to 116.0 ). Multiple regression analysis of these data revealed that both temperature and effective clutch size had significant effects on larval residence time. Together, these two variables explained more than $93 \%$ of the observed variation in residence times $\left(R^{2}=0.934 ; p\right.$ values for the coefficients of both explanatory variables were $<0.002$ ). Increases in either ambient temperature or the number of larvae in a host were associated with a decrease in residence time (the estimated relationship was residence time $=211.2-4.14$ temperature -5.50 effective_clutch size) (Figure 5). By the time all larvae left an infected host, it was common to find all soft tissues inside the cicada's body entirely consumed so that nothing but the exoskeleton remained.

To exit their host, larvae used their oral hooks to burrow through intersegmental membrane, and they usually emerged by squeezing between one of the cicada's opercula and its abdomen (Figure 6). The exact location of egress was observed for 83 larvae from $28 T$. dorsatus hosts, and of these, $64(77.1 \%)$ exited from behind one of the cicada's opercula. Of the remaining larvae, 16 (19.3\%) exited next to the pygofer or terminal abdominal segments at the apex of the abdomen, and $3(3.6 \%)$ burrowed through the membrane between the head and prothorax.

After leaving their host, larvae immediately burrowed into the soil (or sand, in the case of the emergence

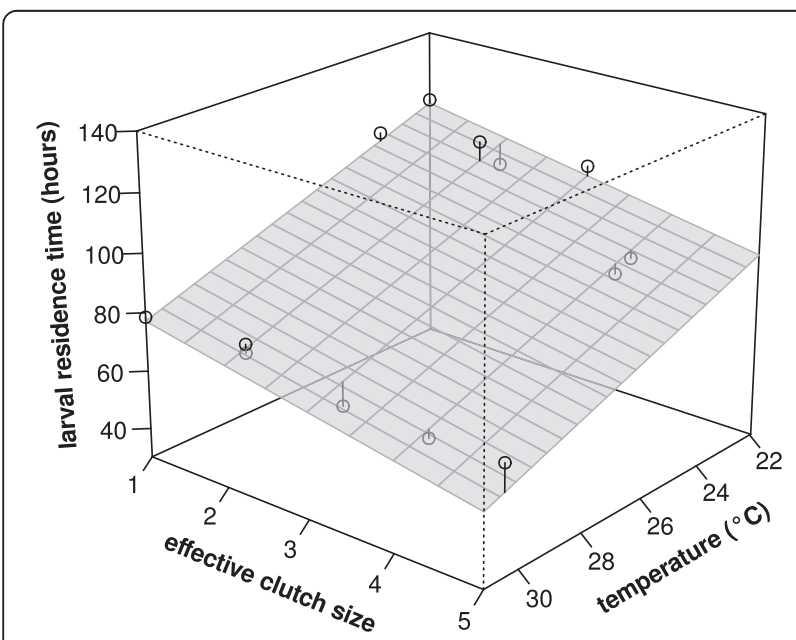

Figure 5 Relationship of effective clutch size and temperature to larval residence time. Each data point represents the mean residence time of the parasitoid larvae inside a single host cicada along with the effective clutch size (number of larvae emerging from the host) and the mean air temperature experienced by the host during parasitoid development. The planar surface represents the multiple linear regression model of the effects of temperature and effective clutch size on larval residence time. Lines connected to the data points indicate the vertical distance of each data point from the regression surface (i.e., the residuals). containers) to pupariate. Although more than 300 E. erro larvae were obtained from infected $T$. dorsatus specimens during the course of this study, relatively few of these were successfully reared to the adult stage. Fiftythree flies survived to adulthood, and the times of both larval egress from the host and adult eclosion were obtained for 31 of these flies. Adult flies eclosed 18.4 days, on average, after leaving their host (95\% CI: 18.02 to 18.69 days, $s=0.91, n=31$ flies from 15 host cicadas, range $=16$ to 20 days). The lifespan of adult flies in the field is unknown. Adult flies maintained in the laboratory survived as long as 92 days.

The lifetime reproductive potential of female E. erro was not determined, but I did dissect 14 gravid female flies that were collected at audio broadcasts of the $T$. dorsatus calling song in 2013 and 2014 and counted all larvae contained within their abdomens. These flies carried as few as 3 and as many as 174 larvae in their incubatory pouches, with a mean of 60.7 larvae per fly ( $s=$ 57.5). The observed distribution of larvae counts was strikingly bimodal: Three flies had more than 150 larvae, while all of the rest had fewer than 80 . The larvae of the four flies with the largest larvae counts were noticeably smaller than those from the remaining flies and generally had less well-developed bristles. Remnants of eggshell were still visible in the incubatory pouches of three of these flies, suggesting that the larvae had recently hatched.

\section{Host parasitism rates and parasitoid loads Parasitism rates}

The results of the $T$. dorsatus population surveys for the prevalence of $E$. erro infection are presented in Table 1. Parasitized $T$. dorsatus were collected at all six of the primary study sites, although infected cicadas were not detected in all population surveys. All parasitoids that were reared to the adult stage were identified as E. erro, and the morphologies of all other larvae and puparia that were obtained were also consistent with E. erro. No hyperparasitoids of $E$. erro were observed.

Across all four sampling years (2011 to 2014) and all six primary study sites, the overall observed parasitism rate for T. dorsatus males was $26.3 \%$ (95\% CI: 21.4 to $31.9 \%, n=266$ cicadas). The surveys in 2014 also included a sample of 28 female $T$. dorsatus from the central KS field sites (in Harvey, McPherson, and Reno counties), and of these, one female cicada was infected with E. erro larvae (3.7\%; 95\% CI: $0.7 \%$ to $18.3 \%$ ).

There was substantial variation in observed parasitism rates among the population samples (summarized in Table 1). The results of the logistic regression analysis suggested that much of this variation was due to differences among field sites, with sampling year possibly also having a small effect (likelihood-ratio tests of field site 


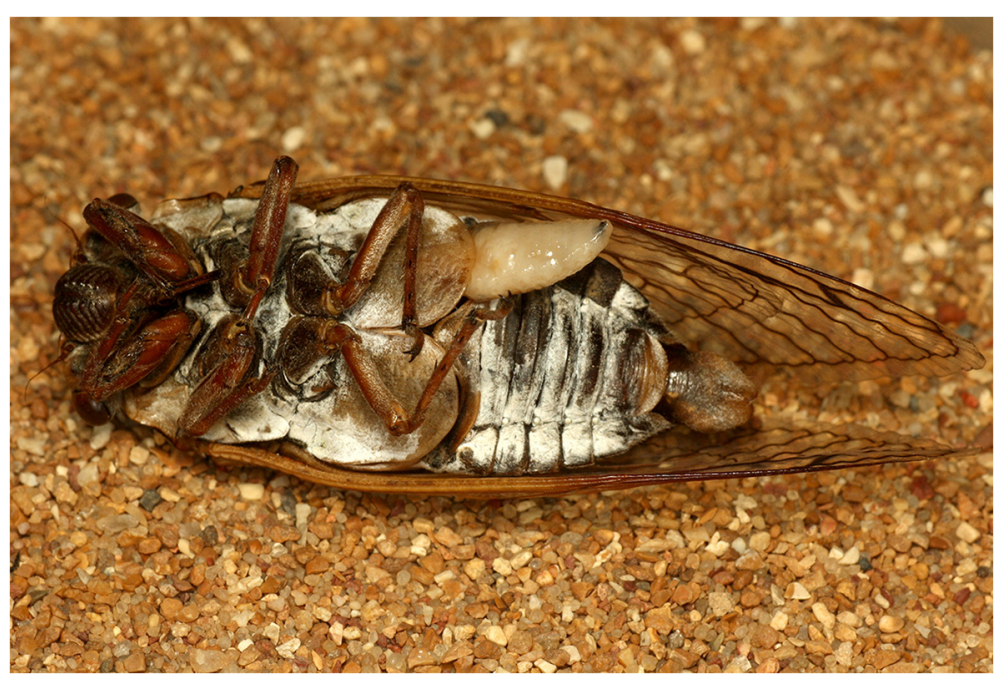

Figure 6 Emergence of $\boldsymbol{E}$. erro from its host. A mature larva of E. erro emerges from between the left operculum and the abdomen of a deceased male T. dorsatus from Prowers Co., CO.

and year as predictors: $p<0.00001$ and $p=0.0663$, respectively). The model including these two predictor variables seemed to explain the data reasonably well, with pseudo $R^{2}=0.549$. Nevertheless, this result must be interpreted with caution. The westernmost field sites often had the highest sample parasitism rates, but because of logistical constraints, these sites were always surveyed later in the summer than the other field sites (Table 1). Thus, the variable field site was at least partially collinear with sample date. Consequently, the high parasitism rates observed at these sites could have been due, at least in part, to seasonal effects rather than inherent site differences.

\section{Parasitoid loads}

The mean parasitoid load of all field-collected infected cicadas was 4.97 larvae/host (95\% bootstrap- $t$ CI: 4.23 to 5.92 larvae/host, $s=3.95, n=91$ hosts, range $=1-19$ larvae/host) and the median was 4 , reflecting the strong right skew of the distribution (Figure 7).

The parasitoid loads of field-collected infected cicadas were often much higher than the clutch sizes of larvipositing females in the laboratory infection trials. A bootstrap- $t$ comparison of means confirmed that the mean clutch size of female parasitoids (2.53 larvae/host) was significantly less than the mean parasitoid load of hosts in the field (4.97 larvae/host) (95\% bootstrap- $t$ CI: 1.32 to 3.52 fewer larvae/host, $p<0.0001$ )

Overall, there was a strong, positive relationship between host cicada parasitism rates and mean parasitoid loads per host (Figure 8), with parasitism rate explaining about $65 \%$ of the variation in mean parasitoid load (simple linear regression: $b=8.29, R^{2}=0.650, p=0.0048$ ). The estimated slope of the relationship was 8.29 , but the imprecision of the parasitism rate estimates meant that this slope estimate likely suffered from attenuation bias. The estimated bias correction factor was approximately 1.117, giving an attenuation-corrected slope estimate of 9.25 .

\section{Discussion}

The results of this study provide the first detailed information about the infection behaviors and life history of any species of Emblemasoma besides E. auditrix. Both laboratory and field observations reveal that E. erro find their hosts by eavesdropping on the sexual communication signals of male cicadas. When a female E. erro locates a calling cicada, she waits to attack until the host is in motion, and larviposition on flying cicadas is not uncommon. The results also show that male $T$. dorsatus are commonly parasitized by E. erro and that there can be substantial variation in population parasitism rates and parasitoid loads. I next discuss the behavior and life history of E. erro, especially in comparison to other acoustic parasitoids and other sarcophagid parasitoids; assess possible host defenses; and discuss possible causes of variation in host parasitoid loads and parasitism rates.

\section{Host locating and infection behaviors of $E$. erro}

E. erro's use of phonotaxis to locate potential hosts is similar to that reported for other acoustically hunting parasitoids (Soper et al. 1976; Lehmann 2003; LakesHarlan and Lehmann 2015), but E. erro's preference for attacking moving targets is apparently unique among known acoustic parasitoids. For example, E. auditrix, the only other Emblemasoma for which larviposition behaviors are known, will aggressively attack stationary or restrained cicadas. Upon finding a male cicada, female $E$. 


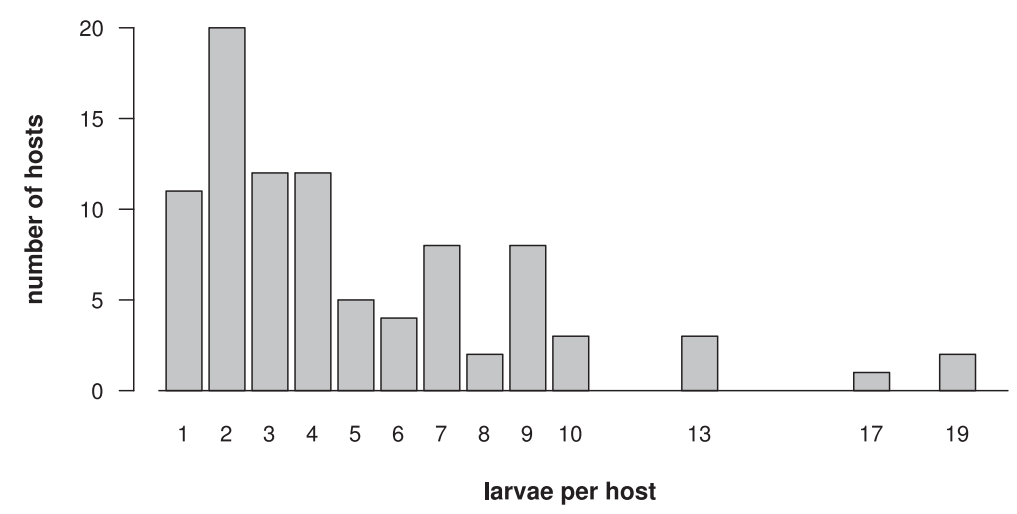

Figure 7 The distribution of parasitoid loads (larvae per host) of infected cicadas in the field.

auditrix exhibit a stereotyped behavioral sequence in which the female fly immediately attempts to squeeze underneath the perched cicada's wings to gain access to the cicada's timbal region. She then uses specialized terminal abdominal sternites to cut through the cicada's timbal membrane and injects larvae directly into the host's body (Schniederkötter and Lakes-Harlan 2004). Female E. erro lack any comparable abdominal modifications, but larvipositing through the host's timbal would likely be impossible for E. erro anyway, because male Tibicen dorsatus have timbals that are fully protected by well-developed timbal covers. In contrast, E. auditrix's host cicada, O. rimosa, lacks timbal covers entirely.

Tachinid acoustic parasitoids of the tribe Ormiini will also attack stationary hosts, and they will even larviposit without visual or tactile confirmation of a host's location. For example, Homotrixa alleni Barraclough, Ormia

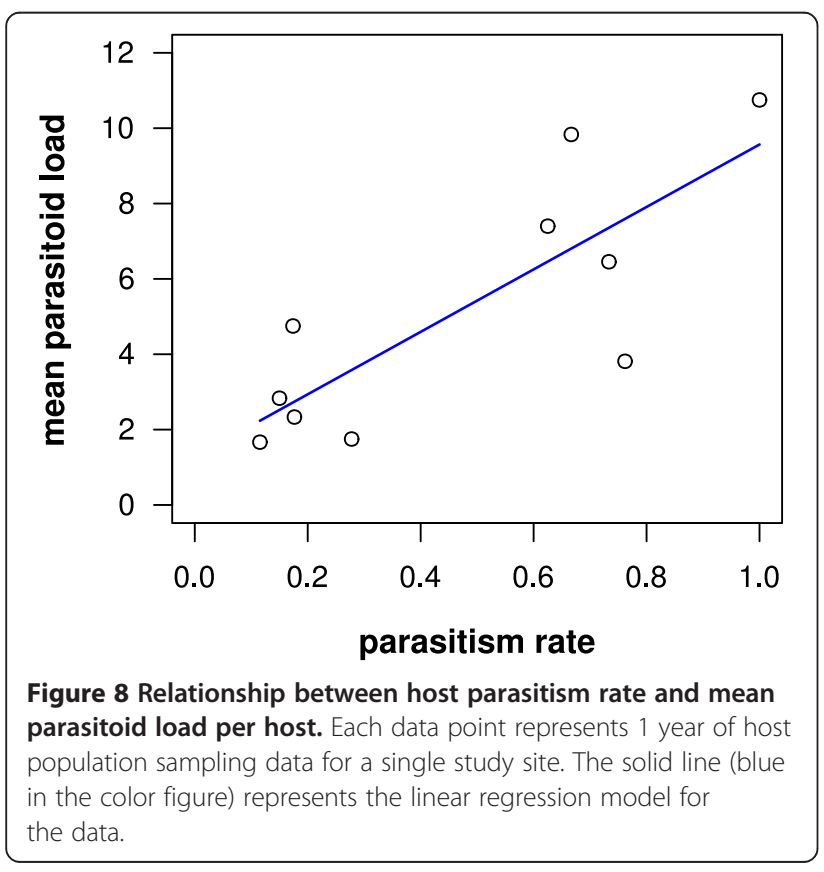

depleta (Wiedemann), and O. ochracea (Bigot) will all deposit larvae at a sound source regardless of whether or not a potential host insect is actually present (Cade 1979; Fowler 1987; Allen et al. 1999). For E. erro, the host's calling song was never sufficient by itself to trigger larviposition, even when a potential host was present. In contrast to E. erro, ormiine tachinids are all nocturnal parasitoids of Orthoptera, and their willingness to larviposit in the absence of a host probably reflects an almost total reliance on acoustic cues at night. For acoustic parasitoids such as E. erro that are active during the day, requiring visual confirmation of a suitable host prior to larviposition allows for more precise placement of larvae and undoubtedly decreases the number of larvae that are wasted by the female fly.

In comparison to the larviposition behaviors of other acoustic parasitoids, E. erro's tendency to attack flying cicadas is especially striking. One third of the successful attacks observed in the experiment cages took place while the cicada was in flight, but this is almost certainly an underestimate of the true frequency of flight-based attacks in nature. Due to the size of the cages used in the trials, most attempts by flies to follow cicadas in the air resulted in failure because the cicada crashed into a side of the cage before the fly could approach and orient itself to the flying cicada. It was hoped that the large'flight cage' would alleviate this problem, but even it appeared to be too small for most aerial attacks to succeed. Nevertheless, flies seemed much more reluctant to attack potential hosts that were not in flight.

This conclusion is further supported by observations in the field, where nearly all apparent larviposition attacks occurred while cicadas were in flight. Flies sometimes even followed a single cicada from perch to perch, waiting patiently next to the cicada each time it landed, but never attempting to attack while the cicada was not flying. As an example, in 2013, I observed a male $T$. dorsatus calling from a grass flowering culm with a female E. erro perched on the opposite side of the stalk near the 
cicada's abdomen. The fly was nearly motionless until the cicada backed a short distance down the stalk, causing the fly to move with him nearly in unison, but the fly made no move to attack the cicada. When the cicada flew a short distance (approximately 1 to $2 \mathrm{~m}$ ) to a new perch, the fly closely followed him in the air, landed next to the cicada, and again remained nearly motionless while the cicada began calling. The cicada flew twice more, with the fly following both times, and after the final flight of at least $30 \mathrm{~m}$, I captured the cicada and later reared two E. erro larvae from it.

While E. erro's behavior of larvipositing on hosts while they are in flight or otherwise in motion might be different from E. auditrix and tachinid acoustic parasitoids, it is remarkably similar to the larviposition behaviors reported for some sarcophagid parasitoids of the genus Blaesoxipha that parasitize acridid grasshoppers. B. aculeata (Aldrich), B. caridei (Brethes), B. kellyi (Aldrich), B. redempta (Pandellé), and B. reversa (Aldrich), among others, have all been reported to attack grasshoppers while in flight (Coquillett 1892; Kelly 1914; Aldrich 1916; Lloyd 1951; Rees 1973; Povolný and Verves 1997). Kelly (1914) provided a detailed description of the larviposition behaviors of B. kellyi, reporting that grasshoppers were attacked either on the wing or on the ground, and that grasshoppers were only attacked when they were in motion (but see Smith 1915). Furthermore, both B. kellyi and B. reversa typically place larvae near the base of a host's wings, much like E. erro (Kelly 1914; Rees 1973).

It is worth noting that early last century, Beamer (1928) and Kelly (1914), both working in Kansas, reported seeing cicadas pursued by flies while in flight. Beamer noted that 'the flies follow but a few inches away, and sometimes seem almost to alight on the body of the cicada.' Although their observations were largely adventitious and incidental, and neither author identified the flies involved, it seems plausible in retrospect that their papers might have been the first published records of $E$. erro's host infection behavior.

\section{Infection of female hosts}

Given E. erro's primary host-finding mechanism, male cicadas are clearly the primary targets of infection by this parasitoid. However, the observation of a fly larvipositing on a female cicada in the laboratory, along with the 2014 survey of female $T$. dorsatus in the field, confirms that female cicadas are also sometimes attacked.

Since female cicadas are silent, how are they discovered by E. erro in the field? One possibility is that, simply by chance, they happen to fly within the visual range of a perched female E. erro. Perhaps more likely, though, female $T$. dorsatus and female E. erro might sometimes encounter one another while seeking male cicadas. Like E. erro, female cicadas perform phonotaxis in response to males' calls, so female cicadas could become parasitized if they were attracted to the same calling male as a female E. erro. In any case, despite many hours spent observing cicadas in the field, I never witnessed any interactions between female E. erro and female T. dorsatus, so such encounters must be rare in comparison to encounters between male cicadas and female E. erro. However, $E$. erro's occasional use of female hosts is not unique. Several other species of acoustic parasitoids that primarily attack male hosts are also known to sometimes parasitize females (Soper et al. 1976; Lehmann 2003).

\section{Phenology and fecundity of $E$. erro}

Little is known of the seasonal phenology of E. erro. In this study, adult flies were observed in the field as early as June 13 (in 2012) and as late as September 4 (in 2014), and these were also the earliest and latest dates that I attempted to find them. The rearing data strongly suggest that E. erro is multivoltine in the geographic area covered by this study. With a total development time from larviposition to adult eclosion of about 22 days, it seems possible that there could be at least three generations per year. $E$. auditrix, in contrast, is apparently univoltine (Soper et al. 1976; de Vries and Lakes-Harlan 2005).

Female E. erro were observed with as many as 174 first-instar larvae, nearly 3.5 times the maximum of 50 observed for E. auditrix (De Vries and Lakes-Harlan 2005). The apparently large difference in fecundity between these two species might be at least partially explained by their larviposition behaviors and life histories. E. auditrix deposits larvae directly inside a host's body, one larva per host, and all available evidence suggests that E. auditrix is a solitary parasitoid (Soper et al. 1976). By injecting larvae into its hosts, E. auditrix likely 'wastes' relatively few larvae during larviposition, and as a solitary parasitoid, it is plausible that multiple larvae inside a single host would physically attack one another (Godfray 1994). Under these conditions, females might benefit by producing fewer, larger larvae to increase their chances of survival. In contrast, because E. erro deposits its larvae on the exterior of a host, it is likely that some percentage of these larvae never manage to make it inside the host's body. Moreover, E. erro is a gregarious parasitoid, and as such, larvae probably face little direct physical aggression from conspecifics (Godfray 1994). For E. erro, then, investing fewer resources in more larvae might increase a female's lifetime reproductive success. Some tachinid acoustic parasitoid species, which deposit their larvae even more haphazardly, also have large larval complements (Wineriter and Walker 1990; Allen et al. 1999; Kolluru and Zuk 2001), and although behavioral data for other sarcophagid parasitoids is extremely limited, at least some parasitoid species in the genus Blaesoxipha also appear to follow this pattern (Middlekauff 1959). 


\section{Host defenses and mortality}

Once discovered by a female E. erro, male $T$. dorsatus appeared to have relatively few viable options to defend themselves. When approached by a parasitoid fly, calling male $T$. dorsatus cicadas responded either by flying, immediately terminating their call and remaining motionless on their perch (hereafter referred to as 'hiding'), or simply continuing their calling behavior. The latter seemed to be the most common. Cicadas often called repeatedly and walked freely about the walls of the experiment cages despite being followed by a fly only a few centimeters away. Cicadas sometimes even called with a fly perched right on top of them. However, stationary cicadas that were directly contacted by a fly would often vigorously flick their wings to try to repel the parasitoid. Unfortunately, given the relatively small space inside the cages, evaluating the effectiveness of any of these behaviors was nearly impossible because a cicada could never truly escape from the fly.

Nevertheless, observations in the field suggested that both the flight and hiding strategies do sometimes work. In at least one case, a fly lost interest in a hiding cicada and left before the cicada resumed calling, and in another, a cicada that was contacted by an approaching fly managed to escape by flying away. Most of the time, though, flies simply waited until a hiding cicada became active again, and they usually had little difficulty in following a flying cicada from one perch to another. As a defensive strategy, flying seems especially risky given $E$. erro's aptitude for aerial larviposition.

After being larviposited upon, cicadas had yet another option for defending themselves. I repeatedly observed cicadas perform 'wing flipping' behavior immediately after being attacked, characterized by rapidly flapping their wings several times while perched. In this way, one cicada managed to completely dislodge the single larva that had been deposited on the cicada's right fore wing, thus avoiding infection completely. This was the only case for which I confirmed that a cicada was able to remove all larvae from its body, but it is possible that some larviposition events were not detected during the behavioral experiments. Wing flipping by $T$. dorsatus appears to be functionally similar to the grooming behaviors used by the cricket Gryllus texensis Cade and Otte to prevent infection by the larvae of Ormia ochracea (Vincent and Bertram 2010).

Although the hosts of some other sarcophagid parasitoids have been reported to occasionally survive parasitism (Spencer and Buckell 1957; Danyk et al. 2000), infection by E. erro appears to be invariably fatal for $T$. dorsatus. In most cases, hosts died several hours before the parasitoid larvae emerged. Host death was usually preceded first by loss of wing function, then loss of leg function beginning with the hind legs and ending with the fore legs. Prior to death, a cicada's antennae were typically the last appendages to display a visible response to external touch. After a cicada died, small, rhythmic movements of the legs or head capsule were often visible as the parasitoid larvae used their oral hooks to scrape muscle and other soft tissue from the integument.

Sometimes, though, when a cicada was infected with only a single larva, the larva emerged before the cicada died, leaving the host in a severely weakened, moribund state. Cicadas in this condition usually succumbed after a few hours. In one exceptional case, a large male $T$. dorsatus from the Prowers Co., CO site that was infected with a single $E$. erro larva survived for more than $24 \mathrm{~h}$ following parasitoid emergence. Although sluggish, it was still able to cling to and crawl on a perch, weakly flutter its wings (but not fly), and was even observed attempting to feed before its movements became uncoordinated and it, too, died. Overall, E. erro must be a major cause of mortality for adult male $T$. dorsatus, especially considering the very high parasitism rates observed in some cicada populations.

\section{Variation in host parasitism rates among study sites}

Host populations at the two westernmost field sites appeared to have consistently higher parasitism rates than sites further east (Table 1, Figure 3). The biogeography of potential host cicadas might offer one explanation for this pattern. The western sites were located on the semiarid High Plains, where there are fewer species of large cicada present than on the more mesic midgrass prairies of the study sites further east. E. erro parasitizes other cicada species besides $T$. dorsatus (B. Stucky, in prep.), so higher parasitism rates of $T$. dorsatus on the High Plains could be a consequence of local differences in the communities of potential host species.

However, as noted in the 'Results' section, because these western sites were also sampled later in the season than the eastern sites, higher parasitism rates could have also been caused by seasonal effects rather than intrinsic differences among the sites. One might expect parasitism rates to increase throughout the season as E. erro populations reach their peak and host populations decline, as has been observed for several other species of dipteran parasitoids, including some acoustic parasitoids (e.g., Tamaki et al. 1983; Allen 1995; Lehmann 2008). It seems likely that this accounts for at least some of the among-site differences in parasitism rates found in this study. Furthermore, both host and parasitoid population sizes undoubtedly also play a role in determining parasitism rates. As evidenced by some of the small population sample sizes, host cicadas were uncommon and difficult to collect for some years at some field sites, which suggests that there was variation in host population sizes from year 
to year. Future studies that estimate host and parasitoid population sizes and sample both High Plains and central Plains sites multiple times throughout the season will be needed to fully disentangle the effects of these variables on host parasitism rates.

\section{Superparasitism by E. erro}

The strong, positive relationship between parasitism rate and parasitoid load (Figure 8), as well as the significant difference between the mean parasitoid load of fieldcollected hosts and the mean clutch size of larvipositing females (4.97 and 2.53 larvae/host, respectively), can both be explained as a consequence of superparasitism in the field. If at least some host cicadas are superparasitized in the field, then we should expect the mean parasitoid load of host cicadas to be larger than the mean clutch size of individual female flies. Furthermore, for gregarious parasitoids such as E. erro, superparasitism is expected to be more common when unparasitized hosts are rare, simply because female parasitoids have a harder time finding hosts that have not already been infected (Godfray 1994). Unparasitized hosts are rare when parasitism rates are high, so higher parasitism rates should correspond with increasing rates of superparasitism. Increased superparasitism would, in turn, likely result in larger parasitoid loads per host, which means that higher population parasitism rates should correspond with higher parasitoid loads. This prediction matches the pattern of the data quite well (Figure 8).

Additionally, anecdotal evidence of superparasitism was found in the relative sizes of larvae emerging from some of the most heavily parasitized hosts. In some cases, two distinct larval size classes were evident, presumably due to the smaller larvae having been deposited on the host later than the larger larvae. In other cases, though, all larvae emerging from heavily parasitized hosts were approximately the same size, suggesting that either a single female deposited all of the larvae at once, or more likely, that two (or more) female flies discovered an uninfected host at nearly the same time.

\section{Conclusions}

E. erro is a widespread, common parasitoid of the cicada T. dorsatus on the grasslands of the Great Plains in the central United States. Female flies locate potential hosts by eavesdropping on the acoustic mating calls of male cicadas, then use visual cues to larviposit on the host while it is in motion. Larviposition often occurs while the cicada is in flight. Parasitization by E. erro is always fatal for $T$. dorsatus, which seems to have few consistently effective defenses against attack. Parasitism rates for male $T$. dorsatus can exceed $70 \%$ in some host populations. Parasitoid loads of infected cicadas average about five larvae per host but can be as high as 19 larvae per host. At least some variation in parasitoid loads is likely due to superparasitism in host populations with high parasitism rates.

Even though E. erro is, like E. auditrix, an acoustically orienting parasitoid of cicadas, the close-range infection behaviors of these two species are highly divergent, and the infection behaviors of both species are very different from tachinid acoustic parasitoids of the tribe Ormiini. Indeed, the infection behavior of E. erro is unlike that known for any other acoustic parasitoid. There are important life history differences between $E$. erro and $E$. auditrix as well: E. auditrix is apparently a solitary, univoltine parasitoid with relatively low larval production per female; E. erro is a gregarious, multivoltine parasitoid with high larval production per female. Given the marked differences between E. erro and E. auditrix, the results of this study suggest that more work is needed to characterize the diversity of Emblemasoma parasitoids. An improved understanding of sarcophagid acoustic parasitoids would make it possible to more meaningfully compare sarcophagid and tachinid acoustic parasitoid lineages, and it would also allow for more robust inferences about eavesdropping parasitoids in general.

\section{Competing interests}

The author declares that he has no competing interests.

\section{Acknowledgments}

I am grateful to the private landowners who allowed me access to their land for this research. I also thank the Kansas Department of Wildlife, Parks, and Tourism, the Harvey County Parks Department, and Colorado Parks and Wildlife for allowing me access to state- and county-owned lands, as well as the employees of these agencies who provided information about the properties they manage. Erin Stucky and Bruce and Pat Stucky spent many hours assisting with field work and data collection; this study would have been much diminished without their help. Greg Dahlem provided helpful advice for how to rear sarcophagid flies. Rob Guralnick, Erin Stucky, and two anonymous reviewers gave valuable feedback on the manuscript and figures, and I also thank the Bowers Lab at CU for helpful commentary on an earlier version of the manuscript. I am very grateful for the financial support provided by research grants from the Department of Ecology and Evolutionary Biology at CU and the University of Colorado Museum of Natural History, and a Sigma Xi Grant-in-Aid of Research award.

Received: 29 October 2014 Accepted: 19 January 2015

Published online: 10 February 2015

\section{References}

Adamo SA, Robert D, Hoy RR (1995) Effects of a tachinid parasitoid, Ormia ochracea, on the behaviour and reproduction of its male and female field cricket hosts (Gryllus spp). J Insect Physiol 41:269-277, doi:10.1016/0022-1910 (94)00095-X

Agresti A, Coull BA (1998) Approximate is better than "exact" for interval estimation of binomial proportions. Am Stat 52:119, doi:10.2307/2685469

Aldrich JM (1916) Sarcophaga and allies in North America, Thomas Say Foundation Series. Murphey-Bivins Company Press, Lafayette, IN

Allen GR (1995) The biology of the phonotactic parasitoid, Homotrixa sp. (Diptera: Tachinidae), and its impact on the survival of male Sciarasaga quadrata (Orthoptera: Tettigoniidae) in the field. Ecol Entomol 20:103-110, doi:10.1111/j.1365-2311.1995.tb00435.x

Allen GR (1998) Diel calling activity and field survival of the bushcricket, Sciarasaga quadrata (Orthoptera: Tettigoniidae): a role for sound-locating parasitic flies? Ethology 104:645-660, doi:10.1111/j.1439-0310.1998.tb00099.x 
Allen GR, Kamien D, Berry O, Byrne P, Hunt J (1999) Larviposition, host cues, and planidial behavior in the sound-locating parasitoid fly Homotrixa alleni (Diptera: Tachinidae). J Insect Behav 12:67-79, doi:10.1023/A:1020929231430

Audacity Team (2012) Audacity: free audio editor and recorder., http://audacity. sourceforge.net/

Beamer RH (1928) Studies on the biology of Kansas Cicadidae. Univ Kans Sci Bul 18:155-263

Beckers OM, Wagner WE (2011) Male field crickets infested by parasitoid flies express phenotypes that may benefit the parasitoids. Anim Behav 82:1151-1157, doi:10.1016/j.anbehav.2011.08.013

Bulmer MG (1979) Principles of statistics. Dover Publications, New York, NY

Cade W (1975) Acoustically orienting parasitoids: fly phonotaxis to cricket song. Science 190:1312-1313, doi:10.1126/science.190.4221.1312

Cade W (1979) The evolution of alternative male reproductive strategies in field crickets. In: Blum MS, Blum NA (eds) Sexual selection and reproductive competition in insects. Academic, New York, NY, pp 343-379

Carpenter J, Bithell J (2000) Bootstrap confidence intervals: when, which, what? A practical guide for medical statisticians. Stat Med 19:1141-1164, doi:10.1002/ (SICI)1097-0258(20000515)19:9 < 1141::AID-SIM479 > 3.0.CO;2-F

Carroll RJ, Ruppert D (1996) The use and misuse of orthogonal regression in linear errors-in-variables models. Am Stat 50:1-6, doi:10.2307/2685035

Cole JA (2008) A new cryptic species of cicada resembling Tibicen dorsatus revealed by calling song (Hemiptera: Auchenorrhyncha: Cicadidae). Ann Entomol Soc Am 101:815-823, doi:10.1603/0013-8746(2008)101[815:ANCSOC]2.0.CO;2

Coquillett DW (1892) Report on the locust invasion of California in 1891. Bull Div Entomol US Dep Agric 27:34-57

Danyk T, Johnson DL, Mackauer M (2000) Parasitism of the grasshopper Melanoplus sanguinipes by a sarcophagid fly, Blaesoxipha atlanis: influence of solitary and gregarious development on host and parasitoid. Entomol Exp Appl 94:259-268, doi:10.1046/j.1570-7458.2000.00628.x

De Vries T, Lakes-Harlan R (2005) Phonotaxis of the female parasitoid Emblemasoma auditrix (Diptera, Sarcophagidae) in relation to number of larvae and age. Zoology 108:239-246, doi:10.1016/j.zool.2005.04.004

Dobson AJ, Barnett AG (2008) An introduction to generalized linear models, 3rd edn, Chapman \& Hall/CRC texts in statistical science series. CRC Press, Boca Raton, FL

Efron B, Tibshirani R (1993) An introduction to the bootstrap. Monographs on statistics and applied probability. Chapman \& Hall, New York, NY

Farris HE, Oshinsky ML, Forrest TG, Hoy RR (2008) Auditory sensitivity of an acoustic parasitoid (Emblemasoma sp., Sarcophagidae, Diptera) and the calling behavior of potential hosts. Brain Behav Evol 72:16-26, doi:10.1159/000139458

Feener DH, Brown BV (1997) Diptera as parasitoids. Annu Rev Entomol 42:73-97, doi:10.1146/annurev.ento.42.1.73

Fowler HG (1987) Field behavior of Euphasiopteryx depleta (Diptera: Tachinidae): phonotactically orienting parasitoids of mole crickets (Orthoptera: Gryllotalpidae: Scapteriscus). J N Y Entomol Soc 95:474-480

Godfray HCJ (1994) Parasitoids: behavioral and evolutionary ecology. Monographs in behavior and ecology. Princeton University Press, Princeton, NJ

Gray DA, Cade WH (1999) Sex, death, and genetic variation: natural and sexual selection on cricket song. Proc R Soc B Biol Sci 266:707-709, doi:10.1098/ rspb.1999.0693

Harrison JF, Woods HA, Roberts SP (2012) Ecological and environmental physiology of insects. In: Ecological and environmental physiology series, vol 3. Oxford University Press, Oxford

Haynes KF, Yeargan KV (1999) Exploitation of intraspecific communication systems: illicit signalers and receivers. Ann Entomol Soc Am 92:960-970

Hedwig B, Robert D (2014) Auditory parasitoid flies exploiting acoustic communication of insects. In: Hedwig B (ed) Insect hearing and acoustic communication, vol 1. Springer Berlin Heidelberg, Berlin, Heidelberg, pp 45-63, http://link.springer.com/10.1007/978-3-642-40462-7_4. Accessed 26 Oct 2014

Kelly EOG (1914) A new sarcophagid parasite of grasshoppers. J Agric Res 2:435-446

Köhler U, Lakes-Harlan R (2001) Auditory behaviour of a parasitoid fly (Emblemasoma auditrix, Sarcophagidae, Diptera). J Comp Physiol A 187:581-587, doi:10.1007/ s003590100230

Kolluru GR, Zuk M (2001) Parasitism patterns and the size-fecundity relationship in the acoustically orienting dipteran parasitoid Ormia ochracea. Can J Zool 79:973-979, doi:10.1139/z01-064

Lakes-Harlan R (2009) Monitoring species distribution of hearing Diptera with sound traps. Fly Times 43:10-12
Lakes-Harlan R, Lehmann GUC (2015) Parasitoid flies exploiting acoustic communication of insects - comparative aspects of independent functional adaptations. J Comp Physiol A 201:123-132, doi:10.1007/s00359-014-0958-3

Lakes-Harlan R, Stolting H, Stumpner A (1999) Convergent evolution of insect hearing organs from a preadaptive structure. Proc R Soc B Biol Sci 266:1161-1167, doi:10.1098/rspb.1999.0758

Lakes-Harlan R, Stölting H, Moore TE (2000) Phonotactic behaviour of a parasitoid fly (Emblemasoma auditrix, Diptera, Sarcophagidae) in response to the calling song of its host cicada (Okanagana rimosa, Homoptera, Cicadidae). Zoology 103:31-39

Lehmann GUC (2003) Review of biogeography, host range and evolution of acoustic hunting in Ormiini (Insecta, Diptera, Tachinidae), parasitoids of night-calling bushcrickets and crickets (Insecta, Orthoptera, Ensifera). Zool Anz J Comp Zool 242:107-120, doi:10.1078/0044-5231-00091

Lehmann GUC (2008) How different host species influence parasitism patterns and larval competition of acoustically-orienting parasitoid flies (Tachinidae: Ormiini). In: Weber EA, Krause LH (eds) Animal Behavior: New Research. Nova, New York, pp 93-132

Lehmann GUC, Lehmann AW (2006) Potential lifetime reproductive success of male bushcrickets parasitized by a phonotactic fly. Anim Behav 71:1103-1110, doi:10.1016/j.anbehav.2005.08.009

Lloyd DC (1951) A survey for grasshopper parasites in temperate South America. Can Entomol 83:213-230, doi:10.4039/Ent83213-9

Lopes HS (1981) Notes on American Sarcophagidae (Diptera). Rev Bras Biol 41:149-152

Maier CT (1982) Observations on the seventeen-year periodical cicada, Magicicada septendecim (Hemiptera: Homoptera: Cicadidae). Ann Entomol Soc Am 75:14-23

McFadden D (1974) Conditional logit analysis of qualitative choice behavior. In: Zarembka P (ed) Frontiers in econometrics, Economic theory and mathematical economics. Academic, New York, pp 105-142

Menard S (2000) Coefficients of determination for multiple logistic regression analysis. Am Stat 54:17-24, doi:10.1080/00031305.2000.10474502

Michelsen A, Nocke H (1974) Biophysical aspects of sound communication in insects. In: Treherne JE, Berridge MJ, Wigglesworth VB (eds) Advances in insect physiology, vol 10. Elsevier, New York, NY, pp 247-296

Middlekauff WW (1959) Some biological observations on Sarcophaga falciformis, a parasite of grasshoppers (Diptera: Sarcophagidae). Ann Entomol Soc Am $52: 724-728$

Müller P, Robert D (2002) Death comes suddenly to the unprepared: singing crickets, call fragmentation, and parasitoid flies. Behav Ecol 13:598-606, doi:10.1093/beheco/13.5.598

Pape T (1990) Revisionary notes on American Sarcophaginae (Diptera: Sarcophagidae). Tijdschr Voor Entomol 133:43-74

Pape T (1996) Catalogue of the Sarcophagidae of the world (Insecta: Diptera), Memoirs on entomology, international. Associated Publishers, Gainsville, Fla

Peterson APG (1980) Handbook of noise measurement, 9th edn. GenRad, Inc, Concord, MA, http://www.ietlabs.com/pdf/Manuals/Handbook_ Noise_Measurement.pdf

Povolný D, Verves Y (1997) The flesh-flies of Central Europe (Insecta, Diptera, Sarcophagidae). Verlag Dr. F, Pfeil, München, FRG

R Core Team (2014) R: a language and environment for statistical computing, $R$ Foundation for Statistical Computing., http://www.R-project.org

Rees NE (1973) Arthropod and nematode parasites, parasitoids, and predators of Acrididae in America north of Mexico. Tech Bull Agric Res Serv US Dep Agric $1460: 1-288$

Robert D (2005) In: Popper AN, Fay RR (eds) Sound source localization. vol 25. Springer, New York, pp 6-35, http://link.springer.com/10.1007/0-387-288635_2. Accessed 26 Oct 2014

Robert D, Miles RN, Hoy RR (1999) Tympanal hearing in the sarcophagid parasitoid fly Emblemasoma sp.: the biomechanics of directional hearing. J Exp Biol 202:1865-1876

Schniederkötter K, Lakes-Harlan R (2004) Infection behavior of a parasitoid fly, Emblemasoma auditrix, and its host cicada Okanagana rimosa. J Insect Sci Online 4:36

Smith HE (1915) The grasshopper outbreak in New Mexico during the summer of 1913. Bull U S Dep Agric 293:1-12

Smith RJ (2009) Use and misuse of the reduced major axis for line-fitting. Am J Phys Anthropol 140:476-486, doi:10.1002/ajpa.21090

Soper RS, Shewell GE, Tyrrell D (1976) Colcondamyia auditrix nov. sp. (Diptera: Sarcophagidae), a parasite which is attracted by the mating song of its host, 
Okanagana rimosa (Homoptera: Cicadidae). Can Entomol 108:61-68, doi:10.4039/Ent10861-1

Spencer GJ, Buckell ER (1957) On the acridiophagous Sarcophagidae of British Columbia with records of all others taken in the province. Proc Entomol Soc Br Columbia 54:29-36

Strauß J, Lakes-Harlan R (2014) Evolutionary and phylogenetic origins of tympanal hearing organs in insects. In: Hedwig B (ed) Insect hearing and acoustic communication. vol 1. Springer Berlin Heidelberg, Berlin, Heidelberg, pp 5-26, http://link.springer.com/10.1007/978-3-642-40462-7_2. Accessed 26 Oct 2014

Tamaki G, Chauvin RL, Burditt AK (1983) Field evaluation of Doryphorophaga doryphorae (Diptera: Tachinidae), a parasite, and its host the Colorado potato beetle (Coleoptera: Chrysomelidae). Environ Entomol 12:386-389

Thornton PE, Running SW, White MA (1997) Generating surfaces of daily meteorological variables over large regions of complex terrain. J Hydrol 190:214-251, doi:10.1016/S0022-1694(96)03128-9

Thornton PE, Thornton MM, Mayer BW, Wilhelmi N, Wei Y, Devarakonda R, Cook RB (2014) Daymet: daily surface weather data on a 1-km grid for North America, version 2., doi:10.3334/ORNLDAAC/1219. Accessed 26 Sep 2014

US Environmental Protection Agency (2013) Level III ecoregions of the conterminous United States., http://www.epa.gov/wed/pages/ecoregions/ level_iii_iv.htm. Accessed 16 Apr 2014

Vincent CM, Bertram SM (2010) Crickets groom to avoid lethal parasitoids. Anim Behav 79:51-56, doi:10.1016/j.anbehav.2009.10.001

Whitlock M, Schluter D (2009) The analysis of biological data. Roberts and Co. Publishers, Greenwood Village, Colo

Wilson EB (1927) Probable inference, the law of succession, and statistical inference. J Am Stat Assoc 22:209, doi:10.2307/2276774

Wineriter SA, Walker TJ (1990) Rearing phonotactic parasitoid flies [Diptera: Tachinidae, Ormiini, Ormia spp.]. Entomophaga 35:621-632, doi:10.1007/ BF02375096

Yack JE (2004) The structure and function of auditory chordotonal organs in insects. Microsc Res Tech 63:315-337, doi:10.1002/jemt.20051

Yager DD (1999) Structure, development, and evolution of insect auditory systems. Microsc Res Tech 47:380-400, doi:10.1002/(SICI)1097-0029(19991215) 47:6 < 380:AID-JEMT3 > 3.0.CO;2-P

Zuk M, Kolluru GR (1998) Exploitation of sexual signals by predators and parasitoids. Q Rev Biol 73:415-438

\section{Submit your manuscript to a SpringerOpen ${ }^{\circ}$ journal and benefit from:}

- Convenient online submission

- Rigorous peer review

- Immediate publication on acceptance

- Open access: articles freely available online

- High visibility within the field

- Retaining the copyright to your article 